\title{
The Meaning of Alternative Sentences
}

\author{
Adrian Leka (PhD Candidate)
}

Ardita Bylo

\section{Doi:10.5901/ajis.2014.v3n2p11}

\section{Abstract}

Draft legislation imposes criminal democratic request for the inclusion of legal instruments that help more in punitive role of the sentence given by the court, by adapting a number of factors and circumstances that cannot accept the classical severity of punishment. This will maximize the peaceful character of the law but also would affect levels significantly above sentence enhancers' purpose. In other words, the criminal law has more need for legal flexibility, giving a considerable assistance and judicial bodies. This flexibility is achieved by using not only clearly defined penalties and stiffly but also creating an amalgam arising from the acquisition of qualitative elements of some types of penalties are available always maintaining sustainable character of the criminal sentence. This flexibility between types of sentences leads us first what is called alternative sentence. Must have a clear alternative that should not understand this notion of broad term for a criminal offense then you can choose punishment of imprisonment or fine, because this determines the choice of law without much skating, but we are dealing with a process which allows us to within a clearly defined type of punishment may be able to detach some other elements of criminal justice thus building a sustainable form of criminal punishment completely featured. Methods of her execution contain essentially what we call the social reintegration of morality offender. Resuming the alternative mentioned above for sentencing will give this definition: the alternative sentence of imprisonment shall mean those sentences given by courts for crimes when the law set distinct criteria which lie within the framework of prison sentences but due to certain circumstances, psychological, moral, family, ways of executing them rigorously regulated by means of isolation are common. Alternative sentencing is not excluded from the punishment. Based on these alternative sentencing court determines the extent of the general rules defined in the law. While suffering with conditional sentencing court a number of factors present as well as how you will behave in the future the prisoner. There are significant differences in terms of the way that making that final decision and the execution in respect of other fixed penalties. Regarding the mode of decision making unlike other court fines wider access in the provision of these convictions. For, although the law sets rigid criteria for these cases again the role of the court is crucial in analyzing and defining the specific circumstances that makes a decision necessary with such character. These circumstances can be very varied, character health, family, professional, moral, where the court must decide each case that when the elements of the relative usefulness for granting an alternative to imprisonment. While related to the form of execution of the sentence here we have a main difference with respect to the manner of execution of the sentence because although alternatives to imprisonment for a legal background has sentence to imprisonment, execution of sentence classical form far from this being done so original executed away from traditional insulation.

Keywords: Court ,punishment, offense, alternatives, probation, Penal Code, prison

\section{The Notion of Conditional Sentencing}

Suspended sentence is suspension of execution of sentence determined for a certain time and with certain conditions. This is a kind of pre-criminal sanction.If the convicted person does not commit the offense provided new deadline, and if it meets the conditions specified by the court which has given the penalty will not be executed and such person shall not be considered convicted. On the contrary, if the person convicted of the condition during the period of suspension of this decision, commits another crime or does not fulfill the other conditions of the sentence suspended, this type of criminal sanction will be revoked and the person shall be sentenced to conditional forced to bear.

Inside his conditional sentence consists of remission of sentence provided to the offender from society. This forgiveness is based on the belief that the offender in the future will respect the law and will not carry the offense. Penalty provided as ad hoc criminal sanction type is shown in the nineteenth century as a result of the knowledge that a number of convicted persons that have committed offenses courts less dangerous to society and persons who committed the act for first time and who have committed the offense due to poor material or the momentary effect of ease of mind or their indiscretion. Punishment provided for the first time presented in U.S.A and in England. This kind of sanction was introduced under the influence of motion for substitution of short-term prison sentences.

The purpose of punishment is provided socialization of delinquent through suspension of sentence. Through 
conditional sentence the offender is seriously warned that the sentence becomes a criminal offense if he carries another sentence suspended for a certain time will be executed. This type of criminal sanction is presented as a method of special psychological - pedagogical attributes of threat in the fight against crime. On the nature of his punishment provided is suitable to be given instead of the prison term for random delinquents in general for the perpetrators of minor offenses.

Based on the many advantages of this type of criminal sanction for cases of offenders was moved above that and the results are achieved with the implementation of his suspended sentence is appropriated almost in all democratic legislation in countries. Also criminal law today is a tendency that the implementation of conditional sentence extended to higher number of offenses.

\subsection{Systems sentence}

There are known three systems of sentence provided in criminal legislations:

1. The Anglo American system is shown in several North American states and in England in the late nineteenth century - as a form of replacement of the imprisonment. First, this system of punishment provided is intended for authors of minor offenses and then for adult authors. As a characteristic of this system is that the perpetrator to criminal procedure, found guilty, but no penalty is given. Giving the sentence suspended for a long time and determines the conditions that must be fulfilled. Also this person at the time of the suspension being convicted placed under special surveillance which carries an officer appointed by the court.

If the author during the time that the court determines not commit any offense and whether it fulfills the other conditions set by the sentencing court shall not be granted at all. Also on the expiration of the time during which the convicted person has been provided trial, which stops any surveillance of persons have filed official.

In the U.S.A sentence may consist of a fine, suspension of sentence, imprisonment or combination of all three.

Penalties in U.S.A require payment of a monetary penalty in favor of the Court. Failure to pay this amount could lead delinquent subject to deprivation of liberty.

Suspension of sentence usually contains various restrictions on travel or behavior, e.g. obligation not to use drugs and alcohol, and not associating with people with serious criminal past.

Suspension of punishment may include placing the person convicted under the strict supervision of an officer or an officer. This person officer is obliged to maintain a periodic report regarding the behavior and actions of the convicted.

U.S.A courts simultaneously-that today they are actively developing the so-called intermediate sanctions. These intermediate sanctions (they include house arrest for weeks or months, observations on the prisoners regarding his communications with friends etc..) in terms of the length of the sentence are less wild than prison but more stringent than the suspension of sentence.

And still comply with these conditions intermediate sanctions to imprisonment exposes the author. While prison sentence represents the essence of a criminal conviction. Though he is not present in any case, he almost always stays an option where a judge has in his discretion to grant it or not. Even when this punishment is not given as the main punishment, he still remains in the background, as a possible consequence of failing, the realization of the conditions of the fine, suspension of sentence, or intermediate sanctions. And still comply with these conditions intermediate sanctions to imprisonment exposes the author. While prison sentence represents the essence of a criminal conviction. Though he is not present in any case, he almost always stays an option where a judge has in his discretion to grant it or not. Even when this punishment is not given as the main punishment, he still remains in the background, as a possible consequence of failing, the realization of the conditions of the fine, suspension of sentence, or intermediate sanctions.

2. Continental European Arrangement is presented at the end of the nineteenth century first in Belgium and in France and for what is called the Belgian - French system. With this system after we acquired the other states of Europe. Characteristic of this system is that conditional sentence the offender is found guilty and the court gives sentence, however given sentence not execute, this will suspend for a specified time provided that the author during this time not commit a new offense, and to fulfill other conditions that the court may designate in the sentence. Unlike the system Anglo - American, Continental Europeans system, during the probation, suspension of execution of sentence, the offender is not assigned any supervision, advice or assistance. This characteristic of the continental European system of suspended sentence is considered as the major bugs since a person on parole whole left without assistance and for this reason can be found in such circumstances and difficulties which may contribute to this again to carry out criminal acts. However, even in some continental European countries, as envisaged in the countries' common law "a declaration of suspension of sentence. And this suspension for special leave to see the reaction of the accused later. 
This behavior depending on the verdict the court gives its decision giving prison sentence or not given the decision at all.

Legislations of these countries in detail anticipating this kind of penalty put the restrictions against him, so that these states restrict the application of the suspension of execution of sentence to:

a. certain categories of offenses authors such as repeaters or strangers, etc..

b. a category of serious offenses that pose serious risks to the public.

A feature that appears in continental European countries is before the court to give such a decision should take the consent of the offender.

So then the offender must give its consent before the court be undertaken such a step. Consent of the accused for this punishment could be considered at least as a preliminary indication of the eventual essential success for any purpose that the court sentence enhancers. This consent is required because the nature of the suspension of sentence's execution is such that this sentence has not the goal and efficiency required if there is a lack of desire and willingness on the part of the author for not committing future criminal acts.

Italian Penal Code as pronounced expression of continental European law suspension of execution of sentence provided in comprehensive manner. Italian courts can make a decision to suspend the execution of sentence for the offense for which a sentence of imprisonment awarded not more than two years or by a fine alone or associated with another penalty.

In such cases the judge may order that the decision to remain suspended (evidence) for a period of 5 years if the conviction is for a felony, and two years for offenses where the punishment is.

IF the offense is committed by a minor until the age of 18 can be ordered suspension when we are dealing with a criminal offense which provides for a criminal penalty of not higher than three years. If the offense is committed by a person who is 18 years old, 21 years old and people over 70 years old, the suspension may be ordered when we are dealing with a criminal offense which provides for a criminal penalty of not higher than 2 years and 6 months (Article 163 IPC)

As for the restrictions, to which the Italian court gives these kind of decisions we have to do with an original system. Suspension of sentence provided under the Italian penal system cannot be given to Article 164 IPC:

- Persons who are repeating in various offenses although they can be forgiven and rehabilitated.

- In cases where the offense must be attached to a personal security measure if the person poses a danger to society public.

- Suspension of execution of sentence cannot be given more than once.

The suspension of sentence may order the fulfillment of certain obligations as returns of items, by paying an amount for liquidated damages incurred tampered behavior that the person you eventually leave road offenses. In any such decision officials must also specify the time when they should be fulfilled such obligations.

Even for effects that can lead to such a decision, they will be interpreted to the extent provided in the suspended sentence given by the court. Except in cases clearly expressed by these acts decision should not become an obstacle or object to stigmatization in society and in working relationships.

A suspended sentence is revoked, then the execution of the Article 168 of IPC :

- A person commits an offense equal to or greater than that for which he was sentenced during the trial period.

- Punished for a previous offense, the punishment that by joining the suspended exceed limits set for the suspension of sentence.

Each of these two systems as one Anglo - American also continental Europeans have advantages and their disadvantages. Anglo priority system - is that the U.S. recognizes supervision which exercises as saw the officer, who watched it offers opportunities for re-socialization of the person convicted. But as the bugs of this system is that in case of revocation of suspended sentence to be administered evidence for assigning correct sentence not working hard up because over time the evidence to be taken into account when deciding on the sentence is too difficult to manage.

The advantage of the system lies in that the continental criminal proceedings terminated by the court at the time when all the evidence is there, which over time is much more difficult to manage. Also this system is cheaper up because does not require the assignment of an officer to monitor and care provided to the person convicted. While the bugs of the system, with the right touch because it does not care at all about the convicted person on bail, does not provide any supervision, care and assistance and for precisely this condition a person sentenced to be found again in those circumstances that may contribute to this offense perform again. 


\subsection{Mixed system}

Given the advantages of both systems aforementioned sentence legislation provided different European countries since the early nineteenth century to the confronted a mixed system comprising elements of system as well as elements of Continental Anglo-American System.

According to this system mixed offender of a criminal procedure given suspended sentence and its execution, but the court may also appoint special surveillance measure for a specified time. In this mixed system of sentence suspended avoid the shortcomings of Continental-European system and the advantages are acquired to Anglo - American the system.

Once treated suspension of sentence under several different systems from Continental European in that the Anglo - American, trying to highlighting the features and advantages as well as disadvantages, let's leap in our system of criminal justice Albanian.

With the adoption of the new Criminal Code in 1995 legislation became our first time a treatment and a full range of alternatives to suspension of execution of sentence of imprisonment and fragmentation of the sentence of imprisonment. Follows analyzing how this code decodes this institute, though has not yet taken such proportions as in European codes for the fact that judicial practice it fails to acquire in properly.

\section{Meaning and Importance of Suspension of Sentence}

Our Criminal Code instead of legal terminology "conditional sentence" that use more codes in different countries use legal terminology "suspension of execution of the decision to jail." Suspension of execution of imprisonment sentence by the court understood the imposition of convicts on probation for a certain period, or conferral of a suspended sentence. Given in the content of Article 59 of the Criminal Code, it appears that we are dealing with a special way of determining the sentence to imprisonment, not executed if the probationary period does not commit another offense as serious as it.

Suspension of the execution sentence of imprisonment sentence preserves the full features of the sentence as state punitive measure, although their term of imprisonment not deemed necessary when there are some circumstances provided for in the Criminal Code that allow for the objective punitive and improve your suspended sentence and its execution by imprisonment.

\subsection{Terms and conditions of the suspension.}

The suspension of imprisonment decision made by the court when these conditions and circumstances exist:

- Firstly when social dangerousness of the offense and the perpetrator is scarce. It is estimated in each particular case by the court for the convicted person taking into account the characteristics of his personality, age minors being that as a rule of eligible persons who have committed the offense under the influence of the immediate circumstances, the previously convicted, the elderly over 70 years old.

- Secondly when circumstances are committing such offense to allow a decision to suspend the execution of sentence. Here is taken into consideration mitigating circumstances commission of the offense provided for by Article 48 of the Criminal Code, if the offense is committed by motivated with positive moral and social values, or under the influence of psychiatric disorder caused by provocation or unfair actions of the victim or to another person, when the person shows deep remorse, etc..

However, the court in the suspension of execution of sentence of imprisonment should be guided primarily by the degree of social danger of the offense concrete, or bull that has brought, circumstances affecting the commission of offenses, the perpetrator's personality, his attitude and other circumstances that convince the court that the guilty isolation from society and their term of imprisonment are not only necessary but sufficient for the announcement of the decision.

In our criminal law is not recommended sentencing expressly provided for persons who have committed offenses before and in particular to specific repeaters. In each case the court shall argue that there are circumstances into account certain penalty for putting on trial. In those cases where the prisoner has committed a serious punishment for example murder, the degree of social danger of the offense and the need to ensure public tranquility by such a person does not allow the suspension of the sentence by imprisonment. In such cases the practice court has given its contribution to the installation of a clear legal framework regarding social suspended sentence. It should be underlined that the fundamental criteria for the implementation of this decision has and the Criminal Code with its provisions. Just suspension of execution 
of sentence by imprisonment is made by the court issuing a sentence by imprisonment of up to five years. Only in such cases the court may order that the prisoner be put on probation by suspending the execution of the sentence but not more than once. Test deadline is 18 months to 5 years and is determined in each case by the court taking into account the personality of the convict and other circumstances. Deadline test is very important moment for the offender, because this is the key moment of the execution or by imprisonment sentence not by the author.

During this period the prisoner should not carry any criminal offense as serious or severe and must also meet any other conditions the court may eventually give him too.

With the offense is so serious we will realize that for which the criminal law provides punishment is that kind of measure how committed the criminal offense of which the first was made for suspension of execution of sentence regardless of the type and extent of punishment that sets court for the offense.

While the most serious offense for which she understood predict the nature and extent of the punishment severe. Including two types of offenses cited above if the condition of the prisoner consumes even if one of them, then the decision of suspending the sentence of imprisonment for the first offense shall be revoked and the unification of penalties.

As mentioned above except that the prisoner during the probationary period shall not commit an offense of the same or greater than that for which he was sentenced, he also occasionally (this puts the court) should implement some conditions and measures which the court deems reasonable for the completion of the test.

\subsection{Measures to be put on trial prisoners.}

Our Criminal Code, Article 60 and its commentary in support of the Criminal Code contain a new treatment on binding measures providing for measures that can be taken to court convicts put to the test. Taking measures against the prisoners put on probation by the court for the rehabilitation of the convicted order to become useful to society, to engage in useful work and to be disconnected from the environment that affects their behavior it's not sticking to the path of criminality. Taking such measures is not mandatory but optional for court so only when the latter deems reasonable and useful purposes of getting them. While other work related stays behind. He is bound in meeting these strict measures imposed by the court.

Court rules taking one or more measures against the prisoners put to the test keeping in mind his personality and the circumstances of the commission of the offense as well as its social dangerousness. Our Penal Code section 60 has listed all measures that mainly court may decide against the prisoners by placing one or more defined these obligations. Among these measures are defined in the code court gives those that are most appropriate, with high efficiency for the rehabilitation of the convicted in the trial taking into account age, occupation, and other properties of his personality, character and significance of offense criminal who has committed, family and social economic conditions in which he lives, social environment with whom he had connections, etc.

So if we are dealing with a new who has no profession or education, then the court compels him to learn a professional activity where primary education or training to obtain relevant professional schools or pursuing different courses. When it comes to condemn what families who have abandoned the court obliges it to pay family pension regularly or when his actions caused the damage or the individual state compels the court to indemnify the civilian damage caused.

If the prisoner has previously committed a violation of the traffic and caused death or injury to persons then run the court prohibits certain vehicles. If the prisoner has previously committed a criminal offense that relates to the exercise of professional activity that prohibits it then exercise such activity.

When a person is convicted of disturbing the peace court decides as to its extent to stay in his apartment at certain hours. If the defendant is convicted of offenses against the person, or public safety, then the court decides that he does not hold for example weapon, for prisoners or mental ill for those using alcohol or narcotics court decides to undergo medical measures against alcohol and various narcotics.

It should be clear that every case is important that the measures to be put in trial prisoners be fully implemented according to the requirements stipulated in the Criminal Code, Article 60, ie. begin implementation of measures under the court's decision and continue to perform to their full. Ordering expressed these measures in our code and it manifests human character do deterrent to crime. But on the other hand it presents great difficulties regarding the control of practical implementation of the measures imposed by the court. In addition to these measures in almost the same form in its decision the court may also add charges that penalize the convict during the trial period. 


\subsection{Obligations of the convict during the trial period}

The aim of these obligations stipulated in the Criminal Code, Article 61 is that the prisoner is subjected feel that control of the supervisor and be disciplined and obedient to the obligations imposed by the court which proves whether the prisoner has improved or not. Under the Criminal Code, Article 61, the obligations are clearly stated as follows:

1. The person convicted is obliged to respond to calls and requests for specific bodies of probation supervision, these bodies may be those of the police, order, or other specific bodies which we call under the supervision of convicts taken up in certain days and hours.

2. Obliged to notify the person convicted oversight bodies for changes in the type of work or profession. This requirement has close relation with the limits of the Criminal Code under which the court determines the type of work that will work and where the prisoner is obliged to respect and implement the decision of the court. In addition to the requirements made to prisoners already informed oversight bodies that the test has to do with this body exercising control over the conduct and behavior of prisoners

3. Duty is another of the prisoners that he received consent to bodies dealing with probation supervision for changing residential center, the employment center and departure abroad also add that these restrictive measures movement to deal with prisoners in order to ensure control of probationary oversight bodies and so on to ensure the execution of the court decision, the respected and implemented legality in criminal law.

Presenting certain conditions in the core of the test suspension of execution of sentence will not realize that the sentence of the court is fully exhausted, it was this or not depends on the completion of these conditions in our criminal law, especially the commentary of the Criminal Code represents a treatment a full revocation of the suspension decision by putting to the test.

\subsection{Terms of the revocation of the suspension decision.}

Revocation of suspension court decision to be made in putting to the test if they have during the term of probation commits an offense as serious or more serious than first offense. Also revocation of the suspension decision by putting to the test done even if the prisoner during the probationary period without good cause has not completed the measures and obligations we quoted above.

Thereby ensure completion of measures and obligations imposed by the court. According to the Commentary to the Criminal Code "without good cause" in cases of noncompliance with these measures and obligations understood that the prisoner deliberately acting contrary to the decision of the trial court with putting. So when there is reasonable grounds such as illness, family distress, force majeure, etc., that have prevented the fulfillment of the obligations imposed measures by court there is no place for revocation of suspended sentence decision.

Besides the conditions and measures which the court decides that the above treated Criminal Code also provides another obligation which covers the suspension of execution of sentence of imprisonment. This obligation is it to perform a job in the public interest.

\subsection{Understanding and establishing conditions of forced labor in the public interest.}

By working in the public interest means any work from its character and content is in the public interest, without prejudice affected the dignity of such person working in the public interest can take place at the municipal service sector, in construction or maintenance of roads in , in the sectors of health, nongovernmental organizations near or in humanitarian sectors.

Replacement of the sentence of imprisonment with an obligation to fulfill a public interest job done when we meet all the conditions of the Criminal Code, namely:

a. the court finds that the social dangerousness of the person is conducted taking into account his personality, his past behavior, the fact that there is habitual, shown remorse for the crime committed, etc.. Also in these cases the court takes into account the commission of the offense, i.e. the importance of the offense, the way the vehicle with which the offense was committed.

b. the court may decide to suspend the sentence of imprisonment for the offense for which the sentence is fixed up to a year in prison, mainly word here is primarily for criminal offenses or serious crimes not envisaged penalties for not more than one year of imprisonment.

c. work in the public interest given by the court for a time from 40 hours to 240 hours, their calculation is done by 
instant. when it is determined by the sentencing court replacement imprisonment up to the moment when completed 240 hours of work in the public interest. Work in the public interest completed within 6 months from the date of entry into force of a court decision, i.e. to 240 hours it must be completed within 6 months. Court determines how many hours and days in which the prisoner will work in a public interest job. This facilitates the accurate calculation of the prison sentence imposed by this court.

d. obligation to work in the public interest determined by the court executed by the prisoner working without any remuneration in favor of the public interest or association determined by the court decision. So for example the court may decide to suspend the sentence of imprisonment to convict and his obligation to work in favor of a non-governmental association of the Red Cross, etc. without any reward.

e. obligation to perform a job in the public interest can not be decided by the court when the prisoner refuses to suspend judicial proceedings, the refusal of the prisoners can be done for various personal reasons when he is sick, or receives better than prison to work in the public interest.

The court is obliged to take account of refusal to convict and decide according to his request. Obligation to work in a job in the public interest cannot be applied to the military court, invalids of the first group, the second, pensioners and other persons unable to work, against minors who have not reached the age of 15 years, employers and employees who have reached 65 years and women 60 years of age. Against these persons may be given a different kind of soft penalty. When the prisoner called to perform military service before or during the punishment, or to perform military service or after may exempt from punishment. These circumstances, although not expressed in law understood by logical interpretation of penal provision. Who is considered unable to work assigned by forensic - legal expertise. When a person becomes unable to work during the execution of the court decision at the request of the Bailiff forced to replace the remainder of the sentence to a fine or a stay of execution or release him from the obligation to work.

f. Our Penal Code provides for the provision of the above amount of the fine in the case of substitution of sentence with work in the public interest with a fine, but it will be settled out of court under Article 34 of the Criminal Code.

g. Court decision for the replacement of the sentence imprisonment, forced to work in a job with the public interest, is effective under the general rules laid down by the court in the Code of Criminal Procedure.

h. In the set hours for work in the public interest calculated missing hours reasonably justified by such medical report that has been ill, or for distress in family.

i. When the prisoner has been arrested or detained and is releasing the days and hours are calculated in the term employed in the public interest.

j. Albanian Criminal Code does not stipulate whether the prisoner to work in the public interest or not there will be other legal consequences, as penitentiary time will be calculated or not in time for the retirement of retirement, invalidity and for effects other financial institutions. Logic demands that this time of the penitentiary not known person for any legal effect. Also convicted person has not paid to citizens why the salary for the time when work is serving the public interest or common license. Surely the Penal Code deficiencies remain to be filled, or with additions of $\mathrm{CC}$, or by judicial practice. However regarding work in the public interest I think, that these provisions of the Criminal Code are probably the only ones that are not really applied our practice court. This stems from many factors.

The money comes from a strong non consolidation of the judiciary in our country, so even if such a decision given our courts are not able to monitor the real execution of this obligation on the part of the convicted.

Second, the application does not come from non structuring or not properly organizing of a civil society throughout its components socio-economic

This leads to what any private entity that welcomes fulfillment of the obligation to convict through its activities or even when such a thing becomes covered by fictitiousness.

\section{Fragmentation of Sentence}

As a means of expression that aims to end resort conviction that our criminal legislation is well aligned sentence fragmentation. Fragmentation of the sentence is a relatively new concept in the modern criminal legislation. He went to meet with the best intentions on reintegration and improvement of delinquent giving opportunity that besides partial execution of the sentence to be involved also in everyday life for himself the surrounding social factors.

Fragmentation in our Criminal Code provided for in Article 58. While the commentary of the Criminal Code makes a 
statement about the meaning and requirements of the fragmentation of the sentence. Under his sentence fragmentation will realize that for convictions on offenses up to a year in prison, the court, upon finding serious family circumstances, medical, professional, health or social decides to execute the sentence, with no less fragmentation than two days a week.

For the fragmentation of the sentence should therefore certain conditions:

1. Fragmentation of the sentence imprisonment be imposed only for those who are sentenced to a year in prison.

2. Fragmentation of the sentence imprisonment is made by the court when it observes serious family circumstances, health, professional and social. With severe family circumstances is perceived when a person has had death to for example family member husband dies of prisoners and children are left without anyone to care for them. With serious health conditions they understand when the sentenced person is suffering from a serious chronic disease that must necessarily be proved however with medical report and assessed by the court that do not allow it to serve a sentence imprisonment. Serious personal circumstances when a person means the introduction in jail for the rest of the sentence could lose his professional skills (surgeon, artist, etc.). While serious social circumstances they understand when a person sentenced to imprisonment has lost the reputation or political or social cause annoyance for example incarceration of a famous footballer, journalist etc.

3. Fragmentation penalty is made by the court in order to execute her convicted by imprisonment for not less than two days a week.

4. The main condition provided in the second paragraph of Article 58 of the Criminal Code is that the execution of imprisonment sentence regardless of how fragmentation is done two or three days a week in prison, should be completed within three years.

5. Penal Code in the third paragraph of Article 58 provides for the revocation of the sentence handed down to fragmentation when:

a. severe family circumstances and social health no longer exist.

b. when the prisoner violates the obligations set out in the decision of the court. With the decision by the court to revoke the prisoner is forced to suffer the remaining part of the sentence in prison. It is understood that the execution of the court decision to sentence Fragmentation requires systematic control of body making special execution of the sentence by imprisonment the execution of judicial or other body charged with this task.

\section{References}

The Criminal Code of the Republic of Albania

Commentary of the Criminal Code (I Elezi, S. Kacupi, M.Haxhiaj ).

Albanian jurisprudence (vellimi3)

The Kanun of Leke Dukagjini

Italian Criminal Code.

Criminal Law and its processes. ( Kadish SCHULHOFER sixth edition ).

Criminalogy and Penalogy (Ragip Halili. Prishtine 1996).

Criminal Law, general part.(C Ismet Salihu - Universiteti i . Prishtines).

Legal Tribune Magazine No.23 -1996.

Probation and Related Measures . (Edition by Council ,of Europa).

The prison study in international organisation and Change. (David Cressey New York 1961,).

Criminology and penology. (J.L.Gillin New York-I 945 ). 